\title{
Taboos as a Social Mechanism Keeping the Human-Nature Balance: Core Values and Practices of Rukai Traditional Ecological Knowledge of Water
}

\author{
Paichi Pat Shein ${ }^{1}$ (D) and Peresang Sukinarhimi ${ }^{1,2, *}$ \\ 1 Institute of Education, National Sun Yat-sen University, Kaohsiung City 804, Taiwan; \\ pshein@mail.nsysu.edu.tw \\ 2 Rukai Cultural Museum of the Indigenous Peoples Culture Development Center, \\ Pingtung County 903, Taiwan \\ * Correspondence: peresangsukinarhimi@gmail.com
}

check for updates

Citation: Shein, P.P.; Sukinarhimi, P. Taboos as a Social Mechanism Keeping the Human-Nature Balance: Core Values and Practices of Rukai Traditional Ecological Knowledge of Water. Sustainability 2022, 14, 2032.

https://doi.org/10.3390/su14042032

Academic Editors: Fernando António Leal Pacheco and Andreas

N. Angelakis

Received: 31 December 2021

Accepted: 3 February 2022

Published: 11 February 2022

Publisher's Note: MDPI stays neutral with regard to jurisdictional claims in published maps and institutional affiliations.

Copyright: (C) 2022 by the authors. Licensee MDPI, Basel, Switzerland. This article is an open access article distributed under the terms and conditions of the Creative Commons Attribution (CC BY) license (https:// creativecommons.org/licenses/by/ $4.0 /)$.

\begin{abstract}
Sustainable water use and management has become an important issue globally and in Taiwan during this era of climate change. In search of a paradigm shift, this grounded theory paper investigates the traditional ecological knowledge (TEK) of a Rukai Indigenous community in Taiwan to unearth its core values and core practices related to sustainability, as its people have been living near the headwaters in the mountain area for generations. Six Elders from the community were interviewed, and the findings show that the Rukai TEK of water is guided by taboos, a social mechanism keeping the human-nature balance, which are ingrained in four core values (prevention of water contamination, group sharing, conservation of the sources of life, and adherence to the laws of nature). These core values are reflected in the five core practices of water use, including calakebe (spring), drakerale (streams), drapulu (ivy fishing), wakaruru (water diversion), and wadrele (water monitoring). These core values and practices contribute to the sustainable environment and livelihood of the Rukai community. This study proposes that positioning Indigenous TEK as the subjectivity of sustainability provides important implications for the sustainable management of natural resources, as well as Indigenous education for sustainable development.
\end{abstract}

Keywords: indigenous; traditional ecological knowledge; Rukai; sustainable water; sustainability; education for sustainable development

Acilai luiyane. salapwane ki niyake. Water, the source of all life. (Rukai language)

\section{Introduction}

With the rise in environmental awareness in the 1970s, the concept of sustainable development also gained increasing international attention. As people began to recognize climate changes and disasters wrought by development activities [1], they also started to understand the importance of considering the interactions and tensions among society, economy, and ecology, and constructing indices for sustainable development [2]. In 1987, the World Commission on Environment and Development published a report entitled "Our Common Future" outlining the definition and principles of sustainable development, in which stated that "humanity has the ability to make development sustainable to ensure that it meets the needs of the present without compromising the ability of future generations to meet their own needs" [3], instilling the concepts of fairness, sustainability, and commonality which have led to a sustainable development model based on balance [4].

Taiwan is ranked as the eighteenth water-scarce country in the world according to the Water Conservancy Agency of the Ministry of Economic Affairs of Taiwan [5]. Due to the steep slopes and concentrated rain, most of the rainwater quickly flows into the ocean; therefore, the average amount of water allocated per person in Taiwan each year is nearly one-fifth of the average rainfall per capita in the world. According to the current 
world standard of water available, Taiwan is a country with severe water shortage. The Sustainable Development Goal 6 proposed by the United Nations notes that we must "ensure that all people have access to water and sanitation and its management" and the sustainability of water resources is the most severe challenge of this era. If we continue to maintain the current production and the model of usage, by 2025, 2/3 of the world population will live in a water-scarce environment [6]. Therefore, raising public awareness of reducing water pollution and water waste behavior will help to ensure sustainable water resources. Moreover, we must ensure that the public actively participates in improving water resources management and sanitation facilities, improving wastewater management, and recycling reclaimed water to achieve sustainable water resources by 2030 .

When people realized that western scientific knowledge could not balance between human development and environmental protection [7,8], academia started to take note of the traditional ecological knowledge (TEK), as it supports coexistence with nature [9,10]. The Canadian government has incorporated the TEK and environmental practices of Indigenous people into national resource management policies [11]. The relevant discourse and research on the applications of Indigenous TEK have been widely discussed in disciplines such as ecological resource use [12,13] and education [9]. Since environmental problems are multiplying daily because of climate change, the TEK of Indigenous people plays a vital role in guiding sustainable development concepts in this century [14].

\section{Sustainability in Indigenous TEK}

Regarding the significance of the TEK of Indigenous peoples for regional sustainable development, Indigenous knowledge is characterized by its maintenance of balance with the ecosystem [14]. This means that Indigenous communities are sensitive to changes in the ecosystem, and such sensitivity forms the basis for determining the mechanisms of production and management. While examining the traditional beliefs of Indigenous peoples, Indigenous cultures entail constraints on the consumption of natural resources and emphasize an understanding of the life cycle of all things [15]. Hence, they carry structural implications that are applicable to the sustainable use of local resources [16].

The concept of TEK can be traced back to 1989, when Robert E. Johannes started to use it in published works at the Internal Union for Conservation for Nature conferences [17]. TEK is a holistic knowledge base that includes cultural continuity, ecological monitoring, coexistence with the environment, continuous adaptation to time and space, and a commonality of experiences shared by community members [18,19]. Moreover, TEK is holistic and cannot be separated from the people, nor compartmentalized in the ways western scientific knowledge has been [20]. TEK is a body of knowledge, practice, and belief that responds to environmental changes and is inherited through several generations [13]. Knowledge refers to the understanding of local species and environmental changes through observing and monitoring. Practice means the ways of using and managing natural resources. Belief is an acceptance that coexistence with the environment is embedded within the ecosystem. TEK includes the ecological practices and knowledge that is built upon the framework of the world views of the Indigenous peoples and reflected through specific traditional cultural practices [21]. From an Indigenous perspective, TEK is about knowing and participating in the relationships among knowledge, people, and the natural/spiritual world; it is a process, not a product, of these experiences [19].

TEK has a mechanism for preserving the ecological environment and maintaining ecological equilibrium, providing the means for human survival and livelihood. TEK is dynamic and adaptive in nature that changes in response to environmental changes; thus, it is almost synonymous to "sustainable use" [12]. To address the conflict between social/economic development and environmental protection, UNESCO held the Man and the Biosphere Programme and the Canadian Environmental Assessment Research Council together with the Canadian Indigenous people in Canada and advocated a sustainable development plan based on the experiences of Indigenous TEK [22]. When the co-management ecological policy is based in Indigenous TEK, it not only affords effective 
environmental evaluation and monitoring, but also establishes the norms of sustainable development, and cultivates cultural recognition by the Indigenous and the non-Indigenous people [7].

This study targeted a Rukai community that is situated in the high mountains near the headwaters and used the grounded theory approach to understand the meanings and values of sustainability within the Rukai TEK of water. The following research questions guided this study:

- What are the core values and core practices of the Rukai TEK of water?

- How is sustainability embedded in the core values and core practices of the Rukai TEK of water?

\section{Methods}

\subsection{Grounded Theory}

The purpose of this study is to investigate the knowledge system of the Rukai TEK of water using grounded theory as the research approach by exploring, summarizing, developing, and verifying textual data [23]. We refrain from using existing theories as the foundation of research analysis to allow the data to reveal itself as it is [24]. Open-ended interview questions were asked to elicit information about the Rukai TEK of water, followup questions were conducted through theoretical sampling to achieve trustworthiness of the data analysis.

\subsection{Research Setting and Participants}

This study is situated in one of the Rukai communities that is at the south end of the central mountain range near the headwaters of the Ailiao North River in Pingtung, Taiwan. The Rukai traditional social structure consists of leaders, noblemen, warriors, aristocratic families, and civilians [25]. Indigenous community leaders possess the rights of land ownership and resources within their traditional territory. Civilians can obtain rights to use land by contracting a lease for the land from Indigenous community leaders or by paying rent [25], or Indigenous community leaders can assign "privileges" to civilians in multiple ways [26].

A total of 6 Elders ( 4 males and 2 females, with age ranging from 51 to 88 years) participated in interviews. Moreover, 10 interviews with a total of $360 \mathrm{~min}$ were conducted. To ensure theoretical saturation and participant resonance, interview participants were selected based on the principle of theoretical sampling, which means that if they find data needing clarification during the initial analysis, researchers can determine upon selecting samples and choosing appropriate participants from whom to collect data through followup visits [12].

\subsection{Data Collection and Analysis}

The semi-structured interviews were conducted at participants' homes or places, such as an open space near a community center, that foster trust and a sense of security, during the interview. Cultural interpreters asked the questions and translated the responses, and we organized participants' responses and asked more in-depth and specific questions in follow-up interviews until participants could not provide meaningful answers. The audio and video data were then transcribed, coded, and summarized. All of the audio, video, and transcribed data of participants were archived according to the guidelines of research ethics to ensure the confidentiality of participants' personal information. To protect the participants' personal information, code names were used. Code names consisted of 3 parts: an uppercase letter (A denoting male; B denoting female), a one-digit number (e.g., 1 denoting the first participant), and stage of interview ("initial", "second", "third", and so on). For example, "A1-initial" refers to the first male participant in his initial interview.

The grounded theory data analysis contained three major stages [12]. First, in the "open-coding" stage, we extracted 45 segments from the interview data and created open codes to label these segments. Second, in the "axial coding" stage, the codes were cate- 
gorized into nine conceptual groups, five are "core practices" and four are "core values". The five core practices include calakebe (spring), drakerale (streams), drapulu (ivy fishing), wakaruru (water diversion), and wadrele (water monitoring). The four core values include prevention of water contamination, group sharing, conservation of the sources of life, and adherence to the laws of nature. Each of the 45 segments may link to multiple conceptual groups as shown in Table 1.

Table 1. Results of core practices and core values.

\begin{tabular}{ccccc}
\hline & \multicolumn{4}{c}{ Core Values (Frequency) } \\
\cline { 2 - 5 } $\begin{array}{c}\text { Core Practices } \\
\text { (Frequency) }\end{array}$ & $\begin{array}{c}\text { Prevention of } \\
\text { Water } \\
\text { Contamination } \\
\text { (16) }\end{array}$ & $\begin{array}{c}\text { Group } \\
\text { Shar- } \\
\text { ing } \\
\mathbf{( 2 2 )}\end{array}$ & $\begin{array}{c}\text { Conservation of } \\
\text { the Sources of } \\
\text { Life } \\
\mathbf{( 1 4 )}\end{array}$ & $\begin{array}{c}\text { Adherence to the } \\
\text { Laws of Nature } \\
\text { (20) }\end{array}$ \\
\hline Calakebe (springs, 12) & 3 & 11 & 1 & 2 \\
Drakerale (streams, 15) & 7 & 5 & 6 & 8 \\
Drapulu (ivy fishing, 4) & 1 & 3 & 2 & 3 \\
Wakaruru (water diversion, 16) & 1 & 10 & 3 & 6 \\
\hline
\end{tabular}

Third, in the "selective coding" stage, the entire data set was re-examined to form a core category, where we found that the concept of tawlrisiane (taboos) links to all four core values (Table 2) and all five practices (Table 3).

Table 2. Results of tawlrisiane in relation to core values.

\begin{tabular}{cc}
\hline Core Values & Tawlrisiane (Taboos, 26) \\
\hline Prevention of water contamination (16) & 13 \\
Group sharing (22) & 13 \\
Conservation of the sources of life (14) & 11 \\
adherence to the laws of nature (20) & 11 \\
\hline
\end{tabular}

Table 3. Results of tawlrisiane in relation to core practices.

\begin{tabular}{cc}
\hline Core Practices & Tawlrisiane (Taboos, 26) \\
\hline Calakebe (springs, 12) & 6 \\
Drakerale (streams, 15) & 10 \\
Drapulu (ivy fishing, 4) & 4 \\
Wakaruru (water diversion, 16) & 6 \\
Wadrele (water monitoring, 9) & 7 \\
\hline
\end{tabular}

In order to attain trustworthiness of the data analysis, we examined consistency and theoretical saturation through cultural expert reviews. We consulted the Elders and cultural experts about the definition of tawlrisiane and found out that it could be considered both as a value system and a social or cultural practice (see Section 4.2 for more details), thus we regard it as a highest guiding principal (or theory) of Rukai TEK of Water.

\subsection{Validity and Reliability}

We validated the results from the data analysis through participant and expert reviews, to ensure the results represent the cultural experience and viewpoints of participants. In the participant review, transcripts were sent to the participants for them to review the content, interpreters helped to recite the content and ask participants for their confirmation or suggestions for revision. The second author assisted in the expert reviews, as well as the entire process of the research, from data collection, data analysis, to writing, as she is a professional who works in Rukai culture and research fields. 


\subsection{Ethical Considerations}

Although we recognize that collaborating with Rukai experts who are knowledgeable in the local culture can reduce the possibility of misunderstanding and misrepresenting research results, whether researchers selectively used data based on subjective values, and other issues related to research colonization, still deserves repeated reflection and inspection [27]. In order to avoid the above issues to the greatest extent possible and to respect the participants as research subjects, this study conducted an ethical review by an external research institute. To ensure the rights and interests of the Indigenous peoples, this research followed the ethical protocols that were approved by the Institutional Review Board and Council of Indigenous Peoples [28]. All members of the research team signed a confidentiality agreement. Before conducting the research, the research team had communicated the academic ethics with the Elders and collected signed informed consent forms as a basis.

\section{Results}

\subsection{Rukai TEK of Water}

Rukai TEK of water is the process that actualizes the "balance" in water resources (Figure 1). The concept of "balance" in Rukai's point of view relates to how people take and use natural resources, because they believe that resources on the earth are limited.

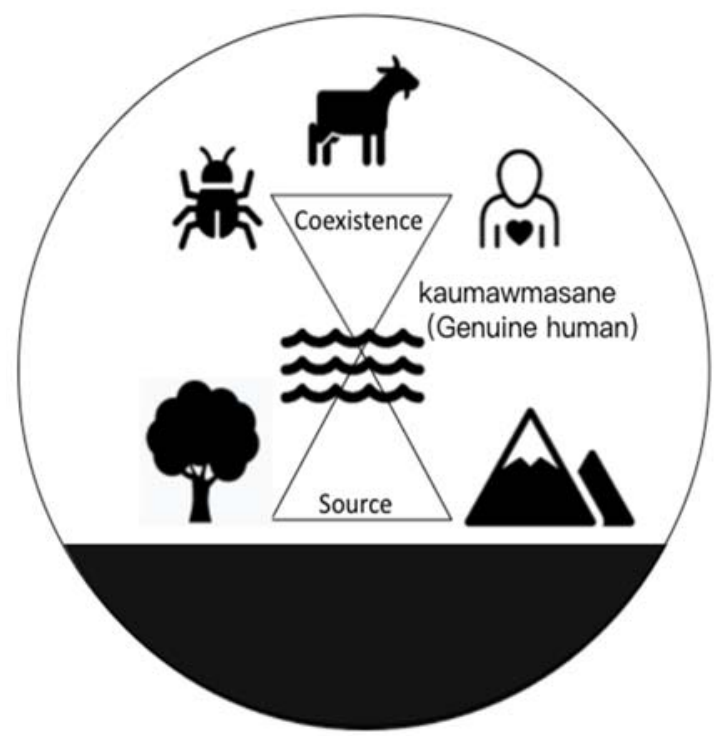

Figure 1. Rukai's view of the balanced relationship between kaumawmasane and the ecosystem.

Rukai people see the ecological system as a "perfect mechanism" that is in balance, and human's behavior acts as a variable that could maintain or disrupt the "balance" (Figure 1). Elders believe that kaumawmasane is one who acts and speaks from the heart and is aware of the impact of personal behavior on others and the overall life cycle (A2-initial); Therefore, kaumawmasane, who acts with abake (a soul that contains both a perceptual heart and a rational mind), plays a key role in keeping the "balance." The Elders consider kaumawmasane as someone who knows what is acceptable and what is not:

"Questions such as 'if I do this, will it affect the surrounding environment or affect other people's land?', or 'will it collapse or not?', must be thought out first" (A2-initial).

Corbin and Strauss [23] suggest the use of diagrams to integrate and refine data to ensure that each conceptual group has internal consistency, and it resonates with the actual experiences. We use the "condition-action/interaction-consequence" paradigm [12] to tease out the conceptual models of Rukai TEK of water and attempt to use illustrations to explain its dynamic process. 
In Figure 2, the infinity symbol represents the meaning of sustainability, and according to Rukai people, balance is synonymous to sustainability. The overarching concept of balance is embedded in the four core values, including prevention of water contamination, group sharing, conservation of the sources of life, and adherence to the laws of nature, which are reflected in five core practices, including calakebe (springs), drakerale (streams), drapulu (ivy fishing), wakaruru (water diversion), and wadrele (water monitoring). Tawlrisiane (taboos) serves as a social control mechanism that maintains the balance between the ecology (water) and the human behaviors. As long-time habitants in the natural environment, the Rukai built in a mechanism of restriction and respect within their cultural organizations and livelihood activities. Within this socio-cultural structure, a person who thinks and acts in accordance with the paradigm is considered and revered as kaumawmasane (a genuine person).

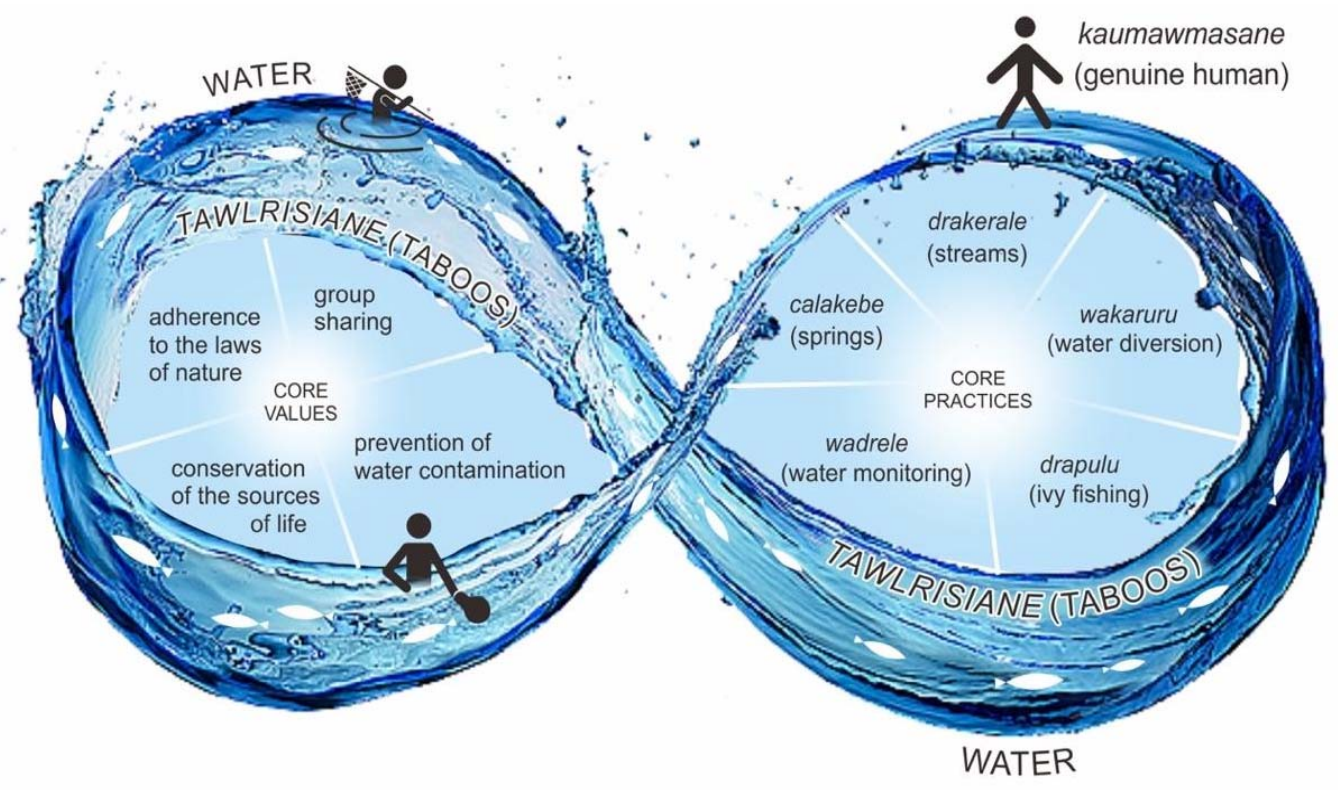

Figure 2. Rukai TEK of Water.

\subsection{Tawlrisiane (Taboos) as a Social Mechanism Keeping the Human-Nature Balance}

According to the Elders, the connotation of tawlrisiane involves action and volition; the external action is guided and regulated by the internal will. Tawlrisiane is the law, norm, and rhythm of human-nature relationships as well as human's self-restraint. It is the foundation that guides how a person should behave in a world that is balanced and sustainable. In other words, tawlrisiane is an action with alertness, mindfulness, and consciousness; it is an important socially constructed element to maintain natural balance and sustainability. The participants in this study all believed that behaviors that violate these taboos can lead to existential crisis for the violator, the entire Indigenous community and living creatures:

"If you take more natural resources than you need or use the resources in an improper way with bad intentions, you will be cursed" (A2-initial).

There are taboos related to the use of water resources. For example, the Rukai consider headwaters to have an inviolable and sacred status (A1-initial). Some river sections such as headwaters or areas with lurking danger should not be disturbed as taboos warn that "there may be formidable evil spirits" (A1-second, B1-fourth).

Taboos are based on the protection of the weak, for example, pregnant women, children, and Elders. These people will never be allowed to go there to gather water; only those of sufficient courage and capability can go there. "You should not develop in those tabooed places; they are the most difficult places to develop" (A3-initial). The tawlrisiane also reveals the core value of preventing water contamination: 
"When hunters go hunting and stay overnight in the mountains, none of the skinned things shall be placed in water. Even the charred pan bottoms shall not be washed in the river. That is one of our taboos. If you do that, the dark clouds will come, and heavy rains will fall, then people will panic" (A1-second).

\subsection{Core Practices of Rukai TEK of Water}

For a deeper understanding of Rukai TEK of water, we present both the local ecological knowledge and its corresponding cultural practices in detail.

\subsubsection{Calakebe (Springs)}

Calakebe is an underground spring, an important water source for traditional Rukai people. They build trenches with stones around the underground spring to make water gathering more convenient (B2-sixth). There are primary and secondary calakebe, categorized based on the volume of water. The primary calakebe never dries up throughout the year, and provides for heavy water use during communal, ceremonial, or ritual events (A3-initial); the secondary calakebe is for daily use. People do not wash their clothes and bodies directly in the calakebe trenches. They must take water out of the trenches with water containers and wash at another place (B2-sixth). When they draw water, people cordially follow the order of their arrival. All of the calakebe in the Indigenous community do not belong to any individual or any household; they are the Indigenous community's public property (A3-initial). It is everyone's responsibility to maintain the calakebe. If a landslide occurs that damages a calakebe or if fallen leaves or garbage accumulate around a calakebe, everyone is obliged to engage in reconstruction and cleaning.

\subsubsection{Drakerale (Streams)}

Drakerale refers to the stream falling from the mountains near a large river. It is the primary place where farmers or hunters use water (A3-initial). In addition, drakerale is the Indigenous community's backup water source. If the calakebe (springs) in the community dries up, then people go to the drakerale to gather water. The norms of drawing water from the drakerale are the same as those for the calakebe, with the only difference being that people shall not wash grains in drakerale. This is because grains washed in the mountain streams will leave chaff, which will flow into the rivers and may pollute the water used by downstream communities (B2-sixth). Moreover, mountain streams located along hunting paths are an important source of drinking water for hunters as they hunt in the mountains. The geographical locations of drakerale and the responsibility to maintain them are critical knowledge and ethics for Rukai hunters (A3-initial).

\subsubsection{Drapulu (Poison Ivy River Fishing)}

Traditional poison ivy (drapulu) river fishing is a form of using river water resources, participants have narrated as follows:

"Drapulu is a type of ioy. When you want to fish in the river, you need to dig out the roots of drapulu, crush them, and squeeze out their juice. Putting the poison ioy juice into the river will temporarily paralyze fish, shrimps, and crabs, which makes it easy to catch them, but the poison ivy juice will not kill the living creatures in the river" (A1-second, A2-initial).

The sustainable use of rivers is intricately rooted in the traditional Rukai social practices, as shown in the public use of the traditional drapulu river fishing:

"To go drapulu river fishing, the first rule is to let all the Elders gather; without them, you cannot do drapulu river fishing" (A1-initial).

"When you do drapulu river fishing, you must calculate the distance of the water flow when the juice is released into the river. The amount of catch shall depend on the number of people eating. In the past, when poison ivy river fishing occurred, the whole community 
would be notified, as well as the exact time when river fishing would happen. Both male and female are welcome to join; if you are available, you should go" (A1-second).

Besides the announcement system, the use of traditional authority to achieve a fair distribution of catch is also highlighted. Indigenous community leaders would specifically assign someone who is an expert at fishing. This person assigned by the leader must take care of those who cannot catch fish and share fish that he has caught with them (A1-second).

Regarding the sustainable use of rivers, traditional drapulu river fishing takes the sustainability of biological reproduction of plants and animals both on the river shores and in the water into consideration:

"The drapulu that has been dug before shall not be dug again, otherwise (the whole plant) will wither. If the amount of fish caught is sufficient, salt should be spread into this section of the river to detoxify the drapulu poison juice in the water. If not, the toxicity of drapulu juice will continue its efficacy in downstream places and make fish there faint as well. During poison ivy river fishing, people refrain from catching fishlings and an excessive number of fish" (A2-initial).

\subsubsection{Wakaruru (Water Diversion)}

The Rukai often integrate cultural values and environmental knowledge as the basis of using water resources, such as sharing (B1-fourth, A3-initial) and using local materials (A1-initial, A1-third). People think that water is not a resource exclusive to an individual, so people ought to think of collective benefit when they develop water sources, tools, and directions of water diversion (A3-initial).

Before people go gather water, they would bring a mountain knife to remove branches that obstruct walking. Besides self-defense, the other purpose of bringing a knife to go to the mountains is to maintain a pre-existed trail for people who will go gather water later (A3-initial). There is wisdom even in water gathering; for example, knowing how to draw water while preventing soil erosion. There were no pipes in the past, but Elders knew how to divert water into fields by using the stems of charcoal trees (trema orientalis) (A1-initial).

\subsubsection{Wadrele (Water Monitoring)}

The way the Rukai use water resources originated from their knowledge in the preservation of water, tree, and soil that is transmitted across the generations (A1-fifth). This means that water is intricately intertwined with the working of the entire ecosystem. The water monitoring knowledge that the Indigenous community has developed includes the coverage of the forest in upper streams (A1-fifth), clarity of river water (A1-second), flow rate of the river (B1-fourth), and other monitoring indices.

The Elders know that trees, water, and soil are interconnected. If one link is missing, the connection is impossible. "So, if there are no trees, you will lose soil; if you lose soil, you will lose water" (A1-fifth). In the past, the indicator of water monitoring was to watch its clarity, to see if it was muddy (A1-second, B1-fourth).

\subsection{Core Values of Rukai TEK of Water}

The Rukai TEK is derived from generations of interaction with the mountainous environment and continues to adapt itself to the changes in social, cultural, and religious value systems. Berkes pointed out that TEK serves the functions of normalizing human behaviors in the community, monitoring the efficient use and preservation of shared resources, and preventing resource exhaustion, and it has the characteristic of flexibly adapting to its environment $[9,12]$. The core values in the Rukai TEK of water originate from the balanced relationship between human and nature, acknowledging the limitations of production in nature [15,29]. There are four core values of Rukai TEK of Water, including prevention of water contamination, group sharing, conservation of the sources of life, and adherence to the laws of nature. 


\subsubsection{Prevention of Water Contamination}

Prevention of water contamination appears in both the calakebe (springs) and drakerale (streams) practices (A1-initial). The main goal is to reduce pollution caused by water use in daily activities, and to prevent safety concerns in the downstream communities. Participants have remarked as follows:

"We pound red quinoa first at home and bring the shelled red quinoa to the calakebe (springs) to wash. The shells of the red quinoa are poisonous. If you take the shelled red quinoa and wash it in valru (rivers), those who live near the drakerale (streams) will be unhappy" (B2-sixth).

Furthermore, during drapulu (poison ivy) river fishing, salt is released in certain areas of the river to detoxify the poison ivy juice in the water; the amount is determined by those who have been participating for many years and are experienced in this activity. The purpose is to effectively prevent the toxicity of poison ivy juice from continuing to flow downstream and contaminating public water resources (A2-initial). An Elder also made the following remark about this:

"The river is where we obtain fish protein and water, same as the people living downstream. So, when we fish by putting drapulu (poison ivy) in the river, we must calculate the distance from upstream to downstream and know that this section belongs to this Indigenous community, and that section belongs to that Indigenous community. This is how you act according to ethics and abide by the social norms" (A1-second).

\subsubsection{Group Sharing}

When participants describe the traditional use of water in the interviews, concepts such as "group," "sharing," and "common" are frequently used, especially in narratives related to traditional livelihood. The core value of "group sharing" can be found in the themes of distributing catch after drapulu (poison ivy) river fishing, drawing water during hunting, distributing taro during harvest shortage, gathering water in calakebe (springs) and drakerale (streams) practices, and diverting water.

When the Indigenous community initiates drapulu (poison ivy) river fishing activity, the experienced Elders would lead the young men to make preparations and guide them to practice the correct ivy fishing steps (A1-initial, A1-second). At the end of the fishing activity, these young people must also distribute their catch equally to the disadvantaged members of the community (A2-initial). In addition, the foundation of sharing is based on concepts of "group" and "common", and since water resources belong to everyone in the community, the responsibility of the prevention of water contamination is also shared amongst the community members. Moreover, it manifests itself when there is a shortage in the harvest due to climate abnormalities:

"When people encounter a poor harvest or a crop failure, they have to figure out how to get through that period of starvation. During that time, those who have paddy fields would harvest taro, and help the households that are in need" (A1-initial).

Calakebe (springs) and drakerale (streams) are not merely names of water sources. They also refer to social behaviors that aligned with the value of sharing:

"You cannot cut in line to get water. If you see baskets that have been there since yesterday, you must fill water for them first. If you do not put water into those empty baskets, your action is similar to theft" (B1-fourth).

"You shall never take water upstream of a water source where someone has discovered. You can only take water downstream. This is a type of ethics" (A3-initial).

It is noteworthy that this core value of sharing the water resource is also present in traditional hunting. Rukai people consider hunting as an activity requiring extensive ecological knowledge and expect hunters to hold high moral standards (A1-second). For example, if hunters draw water from mountain streams, they are responsible for the tidiness 
of the immediate surroundings. When hunters see damaged stone-built water diversion pathways or water storage trenches, voluntarily cleaning and repairing them is viewed as a character trait and a skill that they ought to have (A3-initial). In this regard, participants have expressed the view that hunters' voluntary acts to maintain water resources exemplify the value of sharing, which is to say that the Indigenous community's common values are practiced and transmitted through participating in traditional activities:

"If someone goes up to the mountain and finds a water source (drakerale), he will ask the one who first discovered it if they can share that water source for irrigation or drinking. He definitely cannot just assume that the person who discovered the source is no longer using it, so he can take it. That is not okay. Senior hunters will inform the new hunters that if you get thirsty in the mountains, you can go to those designated mountain streams to draw water for drinking" (A2-second).

\subsubsection{Conservation of the Sources of Life}

The Rukai TEK of water is the result of interweaving local culture and knowledge of the natural environment. It reveals people's sentiments toward nature and normalizes the distant yet intimate distance between humans and nature. Regarding this, participants have made the following comments:

"The natural environment in this world has no room for change. It is perfect the way it is. The only thing humans can do is to appreciate it (nature). However, if your wisdom knows how to use water, then this water becomes your water" (A4-second).

When using water, the Rukai people are aware of their role in not interrupting the "perfect mechanism" that the nature presented:

"Humans are a species that can produce uncleanliness. Thus, if we are at the source (water source and trees that conserve that water source), if we disrupt it and do not keep our distance from it, our existence will be threatened. Therefore, on one hand, you feel the intimacy of nature nurturing you; on the other hand, you must know that it is necessary to keep some distance" (B2-sixth).

As stated above, it can be inferred that Rukai people's concept of the "perfect" natural environment is built upon its original appearance, and humans should keep a distance from it. Otherwise, the "water" will bring disasters (it will not become your water). Moreover, the method to keep such distance is most frequently couched in the concept of tawlrisiane (taboos), which denotes traditional beliefs and legends that frighten people away from potentially dangerous water areas. Tawlrisiane not only prevents the destruction wrought by human exploitation of the headwaters, but also safeguard the Indigenous community and biological ecosystem from being threatened by a deterioration of the natural environment. Tawlrisiane are also instilled with sacredness in traditional beliefs and gratitude toward nature:

"The taboos taught by Elders in the past are that when you see an animal there, you do not disturb it. If there is a snake at the water source, the Elders would warn us not to frighten it and let it live there as it pleases. What the Elders have told us is what their Elders, grandfathers, and grandmothers, have taught them, generation after generation, reminding younger generations. Even today, they are obeying these rules. The tabooed place means it is where animals can grow (reproduce)" (A1-initial).

\subsubsection{Adherence to the Laws of Nature}

The core value of adherence to the laws of nature in the use of water is mainly shown in water diversion, such as adapting techniques to utilize the spring and rainwater, which participants have described as follows:

"This is the Rukai territory, so we know the natural path of water. We should respect the traditional construction method (of water diversion). People change, so when people forget about the culture for the sake of convenience, a crisis emerges. We cannot predict or 
replicate the forces of nature; the past techniques cannot be replaced by modern technology or machinery. So, when we want to develop something, we should think twice" (A4-initial).

When the water diversion method is not available due to the limitations to the terrain, people accept the scarce availability of water or the lack thereof:

"We have the upper land, which makes it inconvenient to divert water. So, we follow the principle of living at the mercy of the above. What to plant during which season? What to eat? Everything is strictly regulated" (A1-initial).

Moreover, the concept of adherence to the laws of nature is also evident in people's knowledge of monitoring and observing the natural and environmental changes in their surroundings, as indicated in the following interview data:

"To determine if a place was abundant in the past, we look at the changes in the river there. For example, if deep pools form in the river after a typhoon, it means that river has vitality; on the other hand, if the water in that river flows rapidly and straight forward after a typhoon and no deep pool is formed, it means that the river has no vitality. When the river does not retain water, people living near it would struggle since they do not have deep ponds to draw clean water from" (B1-fourth).

\subsection{Tawlrisine as the Balancing Agent for Sustainability}

This study found that tawlrisine is embedded in the four core values and the five core practices of water use, which all point to the highest guiding principle of the spirit of balance or sustainability. As Rukai Elders would say, "we must be concerned with the availability of water resources and pay attention to the clarity and turbidity of river water. The condition of river water foretells our future. We must carefully control our desire, footsteps, and hands" (A2-third). Table 4 provides examples for the interconnected relationships between tawlirisine and the core practices and core values.

Table 4. Tawlrisiane in relation to core practices and core values.

\begin{tabular}{|c|c|c|}
\hline & & $\begin{array}{c}\text { Tawlrisiane as a Social Mechanism Keeping the } \\
\text { Human-Nature Balance }\end{array}$ \\
\hline \multirow{5}{*}{$\begin{array}{l}\text { Core } \\
\text { practices }\end{array}$} & $\begin{array}{l}\text { Calakebe } \\
\text { (springs) }\end{array}$ & There are social norms in the use of spring water. \\
\hline & $\begin{array}{l}\text { Drakerale } \\
\text { (streams) }\end{array}$ & $\begin{array}{l}\text { There are social norms in the use of water in streams } \\
\text { and rivers. }\end{array}$ \\
\hline & $\begin{array}{l}\text { Drapulu } \\
\text { (ivy fishing) }\end{array}$ & $\begin{array}{c}\text { Elders are to be gathered to determine the amount of } \\
\text { poison ivy released in the river for fishing to avoid } \\
\text { negative effects on the downstream communities. } \\
\text { People know that they are allowed to only fish at } \\
\text { certain sections of the river. }\end{array}$ \\
\hline & $\begin{array}{l}\text { Wakaruru } \\
\text { (water diversion) }\end{array}$ & $\begin{array}{l}\text { Water resources do not belong to a person or a } \\
\text { household; all people have equitable access to } \\
\text { water resources. }\end{array}$ \\
\hline & $\begin{array}{l}\text { Wadrele } \\
\text { (water monitoring) }\end{array}$ & $\begin{array}{l}\text { Based on the evaluation of the condition of the water } \\
\text { sources, certain behaviors are restricted or } \\
\text { prohibited to keep the water clean and abundant. }\end{array}$ \\
\hline \multirow{4}{*}{$\begin{array}{c}\text { Core } \\
\text { values }\end{array}$} & $\begin{array}{l}\text { Prevention of water } \\
\text { contamination }\end{array}$ & People are refrained from polluting the water source. \\
\hline & Group sharing & $\begin{array}{l}\text { People are refrained from monopolizing the water } \\
\text { source and shall draw water in order. }\end{array}$ \\
\hline & $\begin{array}{l}\text { Conservation of the } \\
\text { sources of life }\end{array}$ & $\begin{array}{l}\text { People are refrained from approaching headwaters } \\
\text { and certain sections of the river to maintain the } \\
\text { sacredness and pristineness of the areas. }\end{array}$ \\
\hline & $\begin{array}{l}\text { Adherence to the laws } \\
\text { of nature }\end{array}$ & $\begin{array}{l}\text { Based on the laws of nature, such as gravity in river } \\
\text { flow and rain patterns in seasons, people are } \\
\text { refrained from behaviors that impact the natural } \\
\text { resources (water, crops, fish, and etc). }\end{array}$ \\
\hline
\end{tabular}




\section{Discussion}

\subsection{Sustainability in the Rukai TEK of Water}

This study attempts to discuss the implications of sustainable development based on the research results in terms of indicators such as fairness, sustainability, and commonality in the realms of environment, culture, and social life. The grounded theory findings show that the Rukai TEK of water included core practices calakebe (springs), drakerale (streams), drapulu (ivy fishing), wakaruru (water diversion), and wadrele (water monitoring), core values (prevention of water contaminations, group sharing, conservation of the sources of life, and adherence to the laws of nature), and the balancing agent of tawlrisiane (taboos).

This study responds to UNESCO's push for reviving and prioritizing the local and Indigenous knowledge systems (LINKS) in its 2017 Report "Local Knowledge, Global Goals." The Report advocates improving the isolated relationship between humans and nature in western science with Indigenous knowledge systems through integration of subjects and interdisciplinary research. The traditional knowledge systems of Indigenous peoples constitute holistic knowledge systems that cannot be easily divided. They provide valuable strategies and references for the improvement of climate changes, environmental disasters, and loss of biological diversity. The knowledge systems of Indigenous peoples play a vital role in global environmental issues today by allowing us to observe the changes in the natural environment from the perspective of the Indigenous worldview of nature and responding to the issue with a scientific method where it seems fit. The contemporary issues and trends of sustainable development have been primarily dominated by western scientific viewpoints [30] until, in 1991 in North America, Canadian officials signed a co-management protocol with Indigenous people [22]. The value of Indigenous TEK application is exemplified in its elaboration of sustainable development.

Radcliffe-Brown [31] defines "taboos" as "ritual prohibitions" or "rules of behavior" in a society. Indigenous people decide when and how to alternate their use of streams, springs, and creeks based on changes in the climate (rainy or dry season). This sense of "rules of behavior" is in Rukai's twalrisiane (taboos) as well. According to the results, twalrisiane is ingrained in the core values and core practices. For the Rukai people, when using the water resource, people comply with the ethical codes, norms, and taboos.

Drapulu (ivy fishing) is the seasonal group river fishing activity that the Rukai community holds. This river fishing method utilizes a natural poison ivy, crushing its roots with stones and squeezing out its juice to be blended into streams. Fish become paralyzed and fall into a coma when they come into contact with the juice of poison ivy, making it easy for people to catch them. The toxicity of poison ivy will not persist inside the bodies of the fish or cause any permanent harm. After some time, the fish will naturally revive. In the traditional culture, drapulu is a fishing activity not performed for a commercial purpose, and it is achieved without the assistance of professional, advanced tools. Therefore, people only fish as much as they can eat by themselves and share with their neighbors. This traditional activity has conditional limitations set by ancestors, such as forbidding catching fingerlings. Experienced Elders are convened for this activity in order to determine the amount of poison ivy juice released in the river based on the volume and flow rate of the river, to ensure that the juice does not affect the downstream communities. Indigenous community leaders must make sure that each household has access to the supply of a certain amount of fish. Since drapulu river fishing pertains to the water safety of the upstream and downstream communities, the norms around river fishing are particularly stringent.

The sustainability of drapulu traditional river fishing is marked by equitable distribution of social resources (fish) and sustainable use of natural resources. Just as drapulu river fishing emphasizes the survival of species by not over-catching and by evenly distributing the catch to ensure a fair and just distribution of food supply. Furthermore, using the "environment, culture, and livelihood" framework of sustainable development to examine drapulu river fishing practice, it is noted that the effort to maintain a balance in the biological and social ecology also allows the core values of group sharing, conservation of sources of life, and adherence to laws of nature to be transmitted to the next generations. 
Before the tap water system became widespread, calakebe (springs) and drakerale (streams) were the primary sources of water resources for the Rukai people in their daily life. For example, people would voluntarily maintain the water-drawing places around mountain streams as they farm or go hunting in the forest, or when there are landslides or fallen leaves and branches clogging up the places. When people draw water, they do not monopolize the water and draw water in order. Moreover, it is a taboo for pregnant women, children, and Elders to go to these two places to draw water. If they did, they could face consequences that threaten their safety, such as hurting themselves by tripping on slippery stones or branches on their paths to draw water.

Wakaruru (water diversion) and wadrele (water monitoring) practices also promote sustainable development among environment, culture, and livelihood. Traditional water diversion practices use local materials to make water diversion tools. For example, the stems of Trema orientalis are hollowed out for use as pipes to divert water from the source to the fields or house backup reservoirs. Traditional water diversion practices are enacted to fulfill the needs of the whole community rather than an individual, a single household, or a family. From the perspective of sustainable development, because this traditional water diversion practice emphasizes the non-privatization of the use of water resources, all people can fairly and equally share water resources. Furthermore, the excessive exploitation of water resources was reduced to avoid the destruction of the ecological system of water resources, because there was only a single water diversion facility and the calakebe (springs) and drakerale (streams) were used in alternation based on weather conditions.

The norms of using water ensure sustainable development as they maintain a stable ecological environment, social order, and livelihood. If one's knowledge and actions achieve the balance of environment-society-livelihood, then one is considered as a kaumawmasane (genuine human); otherwise, one is viewed as an outcast and someone who may beckon cursed consequences for oneself or the community.

The traditional practices of the Rukai TEK of water reveal the intricate and inseparable relationship among ecology and community through fairness in resource distribution and sustainability in environmental use. From the contemporary perspective of sustainable development, the practice of the Rukai TEK directly and indirectly responds to all of the 17 sustainable development goals outlined in the 2030 agenda for sustainable development [32].

\subsection{Indigenous TEK and Educational Sustainable Development (ESD)}

When modern scientific knowledge can no longer sustain the co-existent relationship between human and the environment, Indigenous TEK, along with its concept of sustainable development, has become a popular educational model for recent environmental education [33]. In the 2017 "Local Knowledge, Global Goals" report, UNESCO proposed that science should incorporate the local knowledge of Indigenous people, and further recommended that researchers build partnerships with Indigenous people [34]. The goal is to use Indigenous people's holistic knowledge system (traditional social structure, economic model, and local environmental character) to provide insights for solving climate change, environmental disasters, loss of biological diversity, and other global environmental issues in modern society. Essentially, this report suggested that it is imperative to take Indigenous TEK as the foundation for constructing and advancing Indigenous ESD.

Knowledge relativists and multicultural education researchers also emphasize that TEK should be incorporated in classrooms [35]. It is known from relevant empirical educational studies that Indigenous students often excel when learning new scientific knowledge through the context of the Indigenous culture [36,37] and the Indigenous world views [38], such learning is found to promote Indigenous students' interest in learning about the environment [4]. However, when western modern science is forced into Indigenous education through compulsory mainstream education, it poses a threat to cultural identity and cultural continuity. In light of this, creating a holistic framework around Indigenous 
TEK as the starting point of education for sustainable development [4] has evidently become fundamental in Indigenous education.

The Indigenous perspective and understanding of the natural environment have always been the main focus of TEK research $[39,40]$. For the Rukai people, the world comprises the sky, earth, and spirit; and within the earth dimension contains human and natural spaces. They also consider the natural space as originally a perfect mechanism, so human activity within the space should be constrained, otherwise it will lead to damage and destruction of the whole. Such knowledge was formed through thousands of years that the Rukai have interacted with the mountains and headwaters, and such knowledge is embedded in the social, cultural, and spiritual value systems. The findings show that the Rukai TEK of water is transmitted through social norms and cultural practices, and it is also transmitted through being rather knowing. When Indigenous community members normalize their water-use behaviors towards the community and the environment, thereby embodying the standards of a "genuine human".

In response to the integration of society, economy, and environment in the framework of education for sustainable development [41], the Rukai TEK of water has the following educational implications:

1. It promotes place-based learning in which teachers contextualize learning in the local environment and encourage learners to actively implement environmental actions.

2. It encourages active participation in local environmental activities through selfempowerment.

3. It advocates for local community members to fulfill the ideals of a sustainable economy, society, and lifestyle.

4. It stimulates critical perspectives on social, cultural, and ecological issues, and encourages environmental resolutions that value sustainability.

To implement the Indigenous ESD curriculum, consensus from key educational stakeholders should be garnered. Upon their support, the stakeholders can further assist the integration of internal educational resources (local Indigenous schools, Elders, youth and senior community centers, local cultural museum, and local library) and external educational resources (universities, informal educational institutions, and research institutions). The Indigenous ESD curriculum should centralize and thread TEK across multiple subjects. The pedagogical approach can mirror cultural transmission patterns found in the traditional practices. The educational goal should align with the local Indigenous community's values of "becoming a genuine human," striving to develop competency, attitudes, and skills related to the four core values, "prevention of water contamination, group sharing, conservation of the sources of life, and adherence to the laws of nature." The core practices calakebe (springs), drakerale (streams), drapulu (ivy fishing), wakaruru (water diversion), and wadrele (water monitoring) underling the balancing agent of tawlirisiane (taboos) can be viewed as a database where local culture is blended into the curriculum. Furthermore, Tilbury and colleagues stated that ESD should focus on "viable practical skills," such as critical thinking, problem-solving skills, future planning, and the ability to work and negotiate with others [42]. To nurture these skills, teaching activities can be oriented toward discussion topics as the lesson content, linking broad concepts such as social justice and sustainable development to the students' personal experiences.

\section{Conclusions}

This research not only investigates the core values and core practices of the Rukai TEK of water, but also reveals the connections between them and their compliance to the overarching principle of keeping a balance between nature and people through social mechanisms such as taboos. From the perspective of the Rukai Elders who participated in the research, balance can be observed in the way nature operates, and cultural norms are in place to guide people's volitions and actions in keeping this balance. The four values (prevention of water contamination, conservation of the source of life, and adherence to the law of nature) are internalized wills of balance, and the five practices (springs, 
streams, ivy fishing, water diversion, and water monitoring) are externalized behaviors that maintain that balance; both the internalized wills and externalized behaviors are enforced by the tawlrisiane (taboos) in the cultural design. Twalrisiane in Rukai traditional ecological knowledge of water play a role as a social mechanism that guides human behaviors in harmony with the ecosystems. Positioning Indigenous TEK as the subjectivity of sustainability provides important implications for the sustainable management of natural resources, as well as Indigenous education for sustainable development.

Author Contributions: Conceptualization, P.P.S.; Methodology, P.P.S.; Validation, P.P.S. and P.S.; Formal Analysis, P.P.S.; Investigation, P.P.S. and P.S.; Resources, P.P.S.; Data Curation, P.P.S.; WritingOriginal Draft Preparation, P.P.S.; Writing-Review \& Editing, P.P.S. and P.S.; Visualization, P.P.S. and P.S.; Supervision, P.P.S.; Project Administration, P.P.S.; Funding Acquisition, P.P.S. All authors have read and agreed to the published version of the manuscript.

Funding: This work was supported by Taiwan's Ministry of Science and Technology [grant number 110-2511-H-110-012-MY3].

Institutional Review Board Statement: The study was approved by National Cheng Kung University Human Research Ethics Committee (protocol code 106-249 and 17 November 2017).

Informed Consent Statement: Informed consent was obtained from all subjects involved in the study.

Data Availability Statement: The data presented in this study are available on request from the corresponding author. The data are not publicly available due to ethical considerations.

Acknowledgments: The authors would like to thank the research team and the participating Elders, who have made this study possible; and Kai-Lung Wang and Wen-Cheng Yan for their help with the earlier drafts of this article. Thanks are also extended to the anonymous reviewers for this article.

Conflicts of Interest: The authors declare no conflict of interest.

\section{References}

1. Lee, Y.J. Reinterpretations of Sustainable Development; Department of Cultural Affairs: Taoyuan, Taiwan, 2003.

2. United Nations. Report of the United Nations on the Human Environment; United Nations: Stockholm, Sweden, 1972. Available online: https://goo.gl/gCdq6s (accessed on 20 December 2021).

3. United Nations. Our Common Future; Oxford University Press: Oxford, UK, 1987.

4. Sun, C.H. What is Sustainable Development? Sci. Study Mon. 2001, 45, 4-14. Available online: https://goo.gl/YyMpr6 (accessed on 20 December 2021).

5. Water Resource Agency of the Ministry of Economic Affairs. 2020. Available online: https://www.wra.gov.tw/News_Content. aspx?n=6438\&s=83290 (accessed on 20 December 2021).

6. Maggie, B. The Atlas of Water: Mapping the World's Most Critical Resource; University of California Press: Oakland, CA, USA, 2016.

7. Stevenson, M.G. Indigenous Knowledge in Environmental Assessment. Arctic 1996, 49, 278-291. [CrossRef]

8. Wu, C.H. Application of Indigenous Traditional Ecological Knowledge. For. Res. Nezusl. 2009, 16, 10-18. Available online: https: / / reurl.cc/Goq4d (accessed on 20 December 2021).

9. Berkes, F. Traditional Ecological Knowledge in Perspective. In Traditional Ecological Knowledge: Concepts and Case; Inglis, J.T., Ed.; International Development Research Centre: Ottawa, ON, Canada, 1993; pp. 1-9.

10. Miraglia, R.A. Traditional Ecological Knowledge Handbook: A Training Manual and Reference Guide for Designing, Conducting, and Participating in Research Projects Using Traditional Ecological Knowledge; Alaska Department of Fish and Game Division of Subsistence: Anchorage, AK, USA, 1998. Available online: https:/ / goo.gl/S1UyB6 (accessed on 20 December 2021).

11. McGregor, D. Linking traditional knowledge and environmental practice in Ontario. J. Can. Stud. 2009, 43, 69-100. [CrossRef] [PubMed]

12. Berkes, F.; Folke, C. Linking Social and Ecological Systems: Management Practices and Social Mechanisms for Building Resilience; Cambridge University Press: Cambridge, UK, 1998.

13. Berkes, F.; Colding, J.; Folke, C. Rediscovery of Traditional Ecological Knowledge as Adaptive Management. Ecol. Appl. 2000, 10, 1251-1261. [CrossRef]

14. Agrawal, A. Dismantling the divide between Indigenous and scientific knowledge. Dev. Chang. 1995, 26, 413-439. [CrossRef]

15. Luzar, J.B.; Fragoso, J.M.V. Shamanism, Christianity and Culture Change in Amazonia. Hum. Ecol. 2012, 41, 299-311. [CrossRef]

16. Menzies, C.R.; Butler, C. Introduction: Understanding ecological knowledge. In Traditional Ecological Knowledge and Natural Resource Management; Menzies, C.R., Ed.; University of Nebraska Press: Lincoin, NE, USA, 2006; pp. 1-17. Available online: https://goo.gl/fjqCWw (accessed on 20 December 2021). 
17. Johannes, R.E. Introduction. In Traditional Ecological Knowledge: A Collection of Essays; Johannes, R.E., Ed.; IUCN: Gland, Switzerland, 1989; pp. 5-9. Available online: https://goo.gl/yfvvdq (accessed on 20 December 2021).

18. Chandra, D.V. Re-examining the Importance of Indigenous Perspectives in the Western Environmental Education for Sustainability: "From Tribal to Mainstream Education". J. Teach. Educ. Sustain. 2014, 16, 117-127. [CrossRef]

19. McGregor, D. Linking Traditional Ecological Knowledge and Western Science: Aboriginal Perspectives from the 2000 Stage of the Lakes Ecosystem Conference. Can. J. Nativ. Stud. 2008, 28, 139-158. Available online: https://goo.gl/mf5mT4 (accessed on 20 December 2021).

20. Roberts, K.L. Circumpolar Aboriginal People and Co-Management Practice: Current Issues in Co-Management and Environmental Assessment; Joint Secretariat-Inuvialuit Renewable Resource Committees and Arctic Institute of North America: Calgary, AB, Canada, 1996.

21. Berkes, F. Sacred Ecology: Traditional Ecological Knowledge and Resource Management; Taylor and Francis: London, UK, 1999.

22. Inglis, J.T. Concepts and Cases. In Traditional Ecological Knowledge; Inglis, J.T., Ed.; International Development Research Centre: Ottawa, ON, Canada, 1993; pp. VI-VII. Available online: https://goo.gl/eH4wFM (accessed on 20 December 2021).

23. Corbin, J.M.; Strauss, A. Grounded Theory Research-Procedures, Canons and Evaluative Criteria. Qual. Sociol. 1990, 13 , 3-21. [CrossRef]

24. Corbin, J.; Strauss, A. Basics of Qualitative Research: Techniques and Procedures for Developing Grounded Theory, 3rd ed.; Sage: Thousand Oaks, CA, USA, 2008. [CrossRef]

25. Taiban, S. The Division and Re-construction of Traditional Territory: Re-examining Human-land Configuration and Spatial Change of Kucapungane. J. Archaeol. Anthropol. 2008, 69, 9-44. Available online: https://is.gd/NGU4Em (accessed on 20 December 2021).

26. Hsu, K.M. The Position of Artistic Behavior and Ritual in the Exchange System, from the Viewpoint of Social Stratification: An example of Haucha Village, Lukai tribe. Minzuxue Yanjiusuo Jikan 1986, 62, 179-203.

27. Higgins, M.; Kim, E.-J.A. De/colonizing Methodologies in Science Education: Rebraiding Research Theory-Practice-Ethics with Indigenous Theories and Theoriests. Cult. Stud. Sci. Educ. 2019, 14,111-127. Available online: https://eric.ed.gov/?id=EJ1208501 (accessed on 20 December 2021). [CrossRef]

28. George, L. The Ethics of Research and Indigenous Peoples. In The Handbook of Research Ethics and Scientific Integrity; Ron, I., Ed.; Springer: Cham/Zug, Switzerland, 2020; pp. 675-691. [CrossRef]

29. Magni, G. Indigenous knowledge and implications for the sustainable development agenda. Eur. J. Educ. 2017, 52, 437-447. [CrossRef]

30. McGregor, D. Traditional Knowledge, Sustainable Forest Management, and Ethical Research Involving Aboriginal Peoples; Aboriginal Policy Research Consortium International (APRCi): Toronto, ON, CA, 2010; Volume 28, pp. 227-243. Available online: https: //goo.gl/twLqYA (accessed on 20 December 2021).

31. Radcliffe, A.R. Taboo; Cambridge University Press: Cambridge, UK, 2014.

32. General Assembly. Transforming Our World: The 2030 Agenda for Sustainable Development. 2019. Available online: https: / / www.refworld.org/docid/57b6e3e44.html (accessed on 6 November 2019).

33. United Nations. International Committee for the Protection of the World Cultural and Natural Heritage; Report No. CC-77/CONF.OOl/9; United Nations Educational, Scientific and Cultural Organization: Paris, France, 1977. Available online: https://goo.gl/yjbezi (accessed on 20 December 2021).

34. United Nations. Local Knowledge, Global Goals; United Nations Educational, Scientific and Cultural Organization: Paris, France, 2017. Available online: https:/ / is.gd/niQ8An (accessed on 20 December 2021).

35. Snively, G.; Corsiglia, J. Discovering Indigenous Science: Implications for Science Education. Sci. Educ. 2000, 85, 6-34. [CrossRef]

36. Aikenhead, G. Towards a first nations cross-cultural science and technology curriculum. Sci. Educ. 1998, 81, 217-238. [CrossRef]

37. Ogawa, M. Toward a new rationale of science education in a non-western society. Eur. J. Sci. Educ. 1986, 8, 113-119. [CrossRef]

38. Cobern, W.W. Worldview theory and conceptual change in science education. Sci. Educ. 1996, 80, 579-610. [CrossRef]

39. Ba, Q.X.; Lu, D.J.; Kuo, W.; Lai, P.H. Traditional Farming and Sustainable Development of an Indigenous Community in the Mountain Area-A Case Study of Wutai Village in Taiwan. Sustainability 2018, 10, 3370. [CrossRef]

40. Yuan, Z.; Lun, F.; He, L.; Cao, Z.; Min, Q.; Bai, Y.; Liu, M.; Cheng, S.; Li, W.; Fuller, A.M. Exploring the State of Retention of Traditional Ecological Knowledge (TEK) in a Hani Rice Terrace Village, Southwest China. Sustainability 2014, 6, $4497-4513$. [CrossRef]

41. United Nations. Integrating Education for Sustainable Development (ESD) in Teacher Education in South-East Asia: A Guide for Teacher Educators; United Nations Educational, Scientific and Cultural Organization: Bangkok, Thailand, 2018. Available online: https:/ /is.gd/k1PZLZ (accessed on 20 December 2021).

42. Tilbury, D.; Robert, S.B.; John, F.; Danie, S. Education and Sustainability: Responding to the Global Challenge; IUCN: Gland, Switzerland, 2002. 